\title{
Diferenças e semelhanças entre padrões de interação online em cursos de duas áreas distintas: Bioquímica da Nutrição e Língua Inglesa ${ }^{1}$
}

Susana Cristina dos Reis

UNICAMP/IEL/CAPES

Valdir Silva

UNEMAT

Este artigo discute o provimento de andaimes - scaffolding - de dois processos distintos de interação sócio-pedagógica realizados em ambientes síncronos de comunicação on-line. Os dados analisados referem-se aos registros de chat de um curso de Inglês para alunos de graduação de diferentes áreas e de um curso de Bioquímica da Nutrição (em Língua Materna) para graduandos da referida área e áreas afins. O objetivo deste artigo é verificar quais são as semelhanças e as diferenças que ocorrem nessas duas situações de comunicação, ou seja, nesses dois contextos distintos de produção de conhecimento. Toda a análise está ancorada na teoria sócio-cultural de Vygotsky, na concepção colaborativa de ensino e aprendizagem, e, principalmente, nas categorias de andaime propostas por Bruner et alii (1976). Os resultados apontam a existência de particularidades distintas e semelhantes na forma com que os andaimes são providos nos dois cursos. Há também indícios de que três das seis categorias de andaimes não são representativas das interações realizadas no contexto sócio-pedagógico midiatizado.

This article discusses the process of scaffolding of two different contexts of interaction in online courses. The corpus is composed of online registration of English classes and Biochemistry classes offered on the Internet through the use of chat. This article aims at verifying which are the differences and the similarities between those real contexts of communication, especially how students and teachers produce knowledge in those environments. The analysis is based on the Socio Cultural Theory and the Communicative Approach. The results show particularities in the scaffolding processes and emphasizes that the most important recurrent categories do not represent the real online interaction that occurs in an online pedagogical chat room.

\footnotetext{
${ }^{1}$ Este trabalho foi realizado sob a orientação da Profa. Dra. Denise Bertoli Braga (Unicamp/DLA/IEL) e apresentado como parte do simpósio: A Intermediação da Internet na Cultura de Ensinar e Aprender a Língua Inglesa, no XVII ENPULI, realizado em Florianópolis, SC, em maio de 2003.
} 


\section{Introdução}

A inclusão de novas tecnologias nas práticas de ensino/ aprendizagem possibilitou que novos recursos e canais de interação fossem explorados no ensino de diferentes áreas do conhecimento. Saber utilizar tais inovações de forma pedagogicamente produtiva é um dos desafios que o professor enfrenta atualmente. Por essa razão, é notável a necessidade de se investigar de que maneira esses desafios pedagógicos são discutidos e enfrentados por pesquisadores de diferentes áreas. Através da verificação prática e da proposição de pesquisa é que será possível contribuir para um melhor desempenho dos professores que se aventuram a desenvolver novas práticas de produção de conhecimento em contextos midiatizados.

Apesar da forte resistência ainda existente por parte de alguns educadores às novas tecnologias introduzidas no ensino, há um grande número de vantagens pedagógicas para a exploração desses recursos na sala de aula ou para o oferecimento de disciplinas acadêmicas à distância. Entre as vantagens existentes cita-se, por exemplo, a possibilidade de um maior envolvimento no processo de construção de conhecimento propiciado pelos diferentes ambientes de interação e pela busca de informação, que contribuem para que o aluno passe de um receptor passivo de informações para um construtor ativo de sua aprendizagem (MOTTA-ROTH, 2001), principalmente, ao interagir em situações reais de comunicação e de pesquisa na Rede.

Pesquisas prévias (PAIVA, 2001; MOTTA-ROTH, 2001) já têm apontado que a rede mundial de computadores ( $W W W$ ) facilita essa troca síncrona ou assíncrona de informações, permitindo assim que professores e alunos se comuniquem em ambientes autênticos de interação, mesmo que estejam em lugares distantes. Conseqüentemente, os estudantes têm a oportunidade de colocar em prática os conhecimentos adquiridos na situação pedagógica. Considerando o caso específico da aprendizagem de Língua Estrangeira (LE), o aluno pode, por exemplo, entrar em contato com falantes nativos ou não da língua-alvo estudada, pesquisar o vasto arquivo da $w w w$ sobre diferentes assuntos e aprimorar o seu vocabulário e conhecimento sobre a língua. É possível ainda que professores e alunos desenvolvam atividades de escrita pelo uso de ferramentas como e-mail, chats, listas de discussões e também pela construção de homepages (REIS, 2004). 
Em relação ao trabalho com um conteúdo específico, é possível um maior engajamento dos alunos na busca da produção do conhecimento na área, seja pela participação efetiva dos aprendizes em salas de bate-papo ou pela troca de $e$-mails, ou ainda, no desenvolvimento de atividades de natureza colaborativa com vista ao aprimoramento do conhecimento específico de cada aluno.

Considerando tais possibilidades, o presente trabalho apresenta uma análise comparativa entre duas pesquisas sobre como ocorre a interação sócio-pedagógica entre professor/aluno: a primeira verifica os processos de interação na aquisição de língua inglesa, enquanto a segunda refere-se aos processos de interação que envolvem a aprendizagem de conteúdos específicos da área de Bioquímica da Nutrição (BN) em língua materna. O contraste entre os dois estudos possibilita investigar as semelhanças e as diferenças da comunicação pedagógica dentro de realidades diferentes de ensino que se valem de um mesmo canal de interação - o chat.

\section{Pressupostos teóricos norteadores da prática de ensino adotada nos cursos analisados}

As investigações na área de ensino mediado por computador (EMC), que têm contribuído para as discussões sobre a prática de ensino colaborativo à distância, geralmente se orientam pelos pressupostos teóricos da concepção sócio-cultural. Essa concepção sustenta que o desenvolvimento cognitivo humano se constitui pelas interações sociais e tem como elemento mediador os instrumentos culturais: signos e instrumentos. Segundo Vygotsky (1989), o homem, como sujeito do conhecimento, não tem acesso direto aos objetos materiais. Para acessálos, ele depende da mediação dos sistemas simbólicos de que dispõe: os signos - que visam controlar a psique e o comportamento dos sujeitos na interação social - e os instrumentos técnicos - que têm por finalidade dominar a natureza e outros objetos materiais.

Para Vygotsky (1989), os signos e os instrumentos técnicos são todos de natureza cultural, pois são produtos que surgem ao longo da história das relações humanas, como resultado da convivência em grupo e são exatamente eles que devem ser dominados novamente pela criança na integração social através da percepção, da linguagem, da memória, etc. É no âmbito das negociações lingüísticas que as 
pessoas entram em constante processo de recriação e reinterpretação de informações, de conceitos e de significações, ou seja, de produção de conhecimento. Assim, todas as atividades desenvolvidas pelo sujeito dependem do domínio que ele tem dos instrumentos de mediação. É essencialmente por meio da linguagem - oral, escrita, gestual e sinestésica - que as funções mentais superiores são socialmente formadas e culturalmente transmitidas. Nesse sentido, o conceito de Zona de Desenvolvimento Proximal (ZDP) é central para entendermos como a teoria sócio-cultural explica todos esses processos.

Seguindo as proposições de Vygotsky sobre a ZDP, Antón (1999) sustenta que o professor ou um outro par mais capaz é um elemento importantíssimo no oferecimento de "andaimes" para o aprendiz. A autora refere-se ao conceito de "andaimes", cunhado por Bruner (1966), para explicar como ocorre a interação na negociação de sentidos em LE entre os aprendizes, pois, para a autora, é pela negociação que o aprendiz vai obter conhecimentos lingüísticos, a partir de suas interações com os outros.

\section{A metáfora de "Andaimes" (scaffolding) e suas funções no processo de produção de conhecimento}

Para propor as categorias de andaimes, Bruner e seus colaboradores (1976) se valeram de observações de uma atividade pedagógica realizada entre um professor e crianças com idade entre 3 e 5 anos. A tarefa nessa experiência era a construção de uma pirâmide de blocos de madeira, ou seja, visava possibilitar um contexto em que o professor oferecia às crianças o andaime, necessário para que elas resolvessem os problemas decorrentes da tarefa proposta.

Com base nos resultados das observações do processo de execução da tarefa, os pesquisadores propuseram seis funções de andaimes denominadas e especificadas da seguinte forma:

a) Recrutamento (R) - dirige a atenção dos pares menos competentes para a tarefa;

b) Redução em Graus de Liberdade (RGL) - simplifica ou limita a demanda de tarefas;

c) Manutenção da Direção (MD) - mantém a motivação e o progresso em direção aos objetivos da tarefa; 
d) Ênfase em Traços Críticos (ETC) - chama a atenção do par menos competente para aspectos essenciais da tarefa;

e) Controle de Frustração (CF) - diminui o stress do par menos competente;

f) Demonstração (D) - modela o comportamento, as estruturas lingüísticas desejadas ou os procedimentos preferidos para atingir os objetivos.

Segundo Antón (1999), os andaimes foram originalmente construídos para descrever o desenvolvimento da criança na interação com adultos. Conseqüentemente, o andaime consiste essencialmente no controle do adulto sobre os elementos da tarefa que estão inicialmente além da capacidade de aprendizagem da criança. Esse controle permite que ela dedique um maior grau de concentração para realizar apenas os elementos que estão dentro de sua competência.

É importante dizer também que quando aplicado no contexto pedagógico, o conceito de andaime torna-se uma metáfora adequada para explicar o auxílio prestado pela colaboração mútua na resolução de problemas (e, conseqüentemente, na produção de conhecimento). Conforme aponta Silva (2003, p. 74), o processo de interação social, independente do contexto, é algo extremamente complexo, marcado por uma infinidade de características humanas bastante específicas, tanto as de natureza objetiva, quanto as de natureza subjetiva. Assim, precisar os 'exatos' momentos em que o professor, monitor, tutor e alunos fornecem os andaimes necessários para que o(s) outro(s) supere $(\mathrm{m})$ suas dificuldades é um passo necessário para a melhor compreensão dos fenômenos envolvidos no processo de interação pedagógico online. É pertinente salientar também que o conceito de andaime, embora não faça nenhuma referência ao conceito de ZPD, apresenta uma relação relativamente próxima ao conceito vygotskiano (SILVA, 2003, p. 74).

Entendemos que as funções de andaimes, ainda que descritas para o contexto presencial, podem servir de parâmetro para análise das interações que ocorrem em contextos de ensino à distância. De fato, ao analisarmos as aulas do curso de inglês mediado por computador WebEnglish (WE) e as aulas do curso de Bioquímica da Nutrição (BN), observamos que todas as funções propostas por Bruner e seus 
colaboradores (1976) são recorrentes nas aulas à distância. Optamos neste artigo por apresentar a análise de alguns exemplos mais representativos de andaimes encontrados nas aulas do curso de WE, bem como nas do curso de BN.

\section{Considerações metodológicas}

Neste artigo, contrastamos realidades de ensino distintas e pareceunos pertinente salientar inicialmente as semelhanças e as diferenças encontradas entre os dois cursos. Nesta seção, faremos uma breve descrição de cada curso, com suas respectivas características. Na seqüência, apresenta-remos as semelhanças pedagógicas que dão suporte à prática de ensino realizada nesses dois contextos. Para finalizar, destacaremos algumas das diferenças observadas a partir da análise dos dados dos dois cursos.

\section{Diferenças e semelhanças entre os cursos de WE e BN}

\section{O curso de WebEnglish (WE)}

O curso de WE (http://www.ufsm.br/labler/webenglish) tem por objetivo ensinar a língua inglesa por meio da Internet. Esse projeto compreende o ensino de conteúdos básicos de língua inglesa a serem trabalhados comunicativamente, pelo engajamento do aprendiz em atividades de leitura e escrita relacionadas ao uso de gêneros discursivos eletrônicos tais como e-mail, chat, anúncios pessoais (AP) e homepages pessoais (HPPs).

A partir de uma concepção de ensino comunicativo de LE, fundamentada na inserção do aluno em situações reais de interação e comunicação (WIDDOWSON, 1991; ALMEIDA FILHO, 1993, p. 47-53), o curso de WE procura avançar em direção à concepção sócioconstrutivista de aprendizagem de LE. Para desenvolver essa abordagem, os projetistas do curso visavam elaborar um ambiente de curso mediado por computador em que os alunos são motivados a aprender na medida em que percebem a utilidade e o significado que os conteúdos adquiridos têm para sua própria interação social (WIDDOWSON, 1991), principalmente ao utilizarem a $w w w$ como meio de interação e pesquisa. Com base nesses pressupostos, o curso de WE foi elaborado 
pela equipe do Laboratório de Leitura e Redação (LabLeR), ${ }^{2}$ na Universidade Federal de Santa Maria (UFSM).

Para realizar as aulas do curso de WE ministrado a distância, as interações entre os participantes ocorreram por intermédio do programa ICQ. Por esse canal de comunicação, a professora e os alunos interagiam virtualmente para a negociação e realização das tarefas. Participaram deste estudo piloto 8 alunos.

\section{O curso de Bioquímica da Nutrição (BN)}

Conforme aponta Yokaichiya (2001), a falta de tempo hábil dentro da carga horária estipulada para compor o currículo tradicional das disciplinas de Bioquímica configurava-se como um dos principais empecilhos para a incorporação dos novos conhecimentos gerados na área. Além da importância da chegada desses novos conhecimentos para os alunos, havia também, por parte deles, um grande interesse em adquiri-los. Uma das saídas para tal situação, como mostra a autora, foi o oferecimento de disciplinas optativas sobre temas específicos de Bioquímica, porém não mais na modalidade presencial, mas sim à distância e via computador (http://ensino.ibi.unicamp.br/curso1). Surgia, assim, o curso virtual de Bioquímica da Nutrição. ${ }^{3}$

\footnotetext{
${ }^{2}$ O LabLeR, projeto financiado pela FAPERGS (Novembro/1997), é um laboratório do Curso de Letras na UFSM, que tem por objetivo geral proporcionar aos alunos um ambiente de pesquisa, investigação e produção de material didático. Entre os objetivos específicos desse projeto temos: 1 . Inserir o aluno de Letras, desde o início do curso, na prática profissional do ensino de língua, com ênfase em leitura e redação; 2. Propiciar uma educação continuada ao profissional em serviço, bem como uma participação ativa em projetos de produção de conhecimento e de elaboração de material didático para o ensino de línguas; 3. Criar um território de investigação e experimentação na área de análise do texto e do discurso, com foco em ensino e aprendizagem de línguas. (http://www.ufsm.br/labler).

${ }^{3}$ Esse curso foi financiado em 1997, pela CAPES, através do Programa de Apoio à Integração Graduação/Pós-Graduação (PROIN/1997- Projeto Integrado para Graduação/Pós-Graduação para o Ensino de Bioquímica). Foi instituído o programa de formação pedagógica através dos cursos de pós-graduação em Bioquímica, vinculados aos Departamentos de Bioquímica do Instituto de Biologia da Unicamp e do Instituto de Química da USP. O grupo de pesquisa, formado por professores da área de bioquímica das duas instituições, tinha como uma das principais atribuições a exploração de temas específicos da área em questão.
} 
Para Yokaichiya (2001), essa forma de ensino constitui-se em uma alternativa bastante atraente para a difusão de conhecimentos específicos e para o atendimento de uma clientela que não tinha possibilidade de cursar disciplinas oferecidas na forma convencional. O curso de Bioquímica da Nutrição (BN) via computador foi totalmente estruturado com base na concepção colaborativa de ensino e, principalmente, de aprendizagem, concepção essa fundada na teoria sócio-cultural. Vale observar que esses mesmos pressupostos orientavam também o curso em sua modalidade presencial, ou seja, todo o projeto de construção do curso virtual foi pensado de forma a assegurar que os participantes - professores, alunos e equipe técnica - pudessem interagir socialmente por meio dos recursos tecnológicos de comunicação: a) o e-mail, para comunicação entre alunos, professores/monitores e corpo técnico; b) salas de discussão (chats), para abordagem de temas pré-determinados; e a c) lista de discussão, para os debates acerca das questões que surgiam durante a realização dos módulos, ou seja, as dúvidas dos alunos e de monitores. Outra possibilidade prevista era também uma lista criada pelo monitor para tratar de algum tema específico que ele entendia ser de relevância para o conhecimento na área da bioquímica.

O curso oferecido em $2001^{4}$ contou com a participação de 47 alunos de graduação e com 8 professores/monitores do curso de pósgraduação do curso de Bioquímica.

\section{As semelhanças e as diferenças pedagógicas e tecnológicas dos cursos}

Algumas semelhanças recorrentes nos cursos anteriormente descritos devem ser destacadas. Primeiramente, a modalidade proposta em ambos os cursos é um elemento comum, pois se dá à distância pela Internet. O canal de interação usado entre os participantes foi o chat, que se constituiu na ferramenta mediadora para o desenvolvimento das práticas de ensino em ambos os casos.

\footnotetext{
${ }^{4}$ Essa versão do curso de Bioquímica da Nutrição (a primeira ocorreu em 2000) foi tomada para análise das discussões das Salas de Discussões (chats pedagógicos) e encontra-se melhor detalhada na dissertação de mestrado intitulada: Interação social e estratégias lingüisticas no processo de provimento de andaime - scaffolding - em uma disciplina de bioquímica da nutrição oferecida a distância via computador(SILVA, 2003 - DLA/IEL/UNICAMP).
} 
O uso da ferramenta chat proporcionou uma análise bastante produtiva das interações colaborativas, pois os alunos foram divididos por sala (chat), para facilitar ao professor o gerenciamento dos turnos das mensagens dos alunos. Em cada sala tinha, no máximo, cinco alunos e um professor para mediar as discussões. Um recurso utilizado foi o de registrar automaticamente todas as discussões estabelecidas em cada chat, um mecanismo que garantia o acesso aos debates ocorridos nas aulas, tanto pelos alunos que ficavam impedidos de participar de alguma discussão, quanto pelos professores que quisessem se valer dos registros para melhor encaminhar suas aulas e ter ciência do nível de participação de cada aluno.

No curso de BN, o professor debatia com os participantes os textos já estudados previamente, uma vez que eles eram disponibilizados no site e podiam ser obtidos por meio da função download. As discussões, tanto no curso de WE quanto no de $\mathrm{BN}$, se davam na forma síncrona. No entanto, no de WE os alunos tinham acesso aos conteúdos durante a interação online, o que possibilitava discutir as tarefas propostas e receber as orientações da professora no chat. Já no de BN, o aluno, a partir das leituras prévias, interagia no chat com o professor e com os outros alunos para discutir e compreender, colaborativamente, algum conceito especifico da área.

Ao desenvolver a interação com os alunos na sala de bate papo, problemas com as tecnologias computacionais subjacentes são detectados, dentre os quais destacam-se problemas de conexão. Além disso, a necessidade de letramento eletrônico de alunos e professores é uma preocupação recorrente em ambos os contextos de ensino.

A infobetização ${ }^{5}$ dos aprendizes para atuar em contextos digitais é um requisito essencial para que o andamento das tarefas seja satisfatório. Com vista a superar esses tipos de problemas, o curso de $\mathrm{BN}$ adotou uma estratégia interessante. Antes do início do curso foram oferecidas aos participantes duas semanas de interação livre para que eles pudessem se familiarizar com possíveis problemas técnicos que poderiam surgir durante o uso de diferentes tecnologias tais como chat, fórum, e-mail, download, envio de formulários, acessos, etc. Nessas

\footnotetext{
5 Mesmo que letramento digital, a infobetização diz respeito à alfabetização eletrônica ou à habilidade com o uso de recursos eletrônicos (BUZATO, 2001; MOTTA-ROTH et al, 2000).
} 
situações, quando um problema técnico surgia ou os participantes tinham alguma dúvida, eles podiam solucioná-los através do suporte técnico, disponibilizado no curso para esse fim.

Com relação às orientações sobre o uso da tecnologia no curso de WE, não havia previsão para discussão sobre esse tópico. No curso havia um tutorial com instruções sobre os diferentes recursos encontrados e sobre alguns procedimentos previamente previstos para a atuação dos alunos. Ao construir o curso, acreditou-se que os alunos iriam ler as instruções fornecidas pelos projetistas do material. No entanto, nem todos os alunos se interessaram por fazê-lo.

A literatura tem indicado que a necessidade de desenvolver o letramento eletrônico entre os aprendizes é essencial, uma vez que conhecer os recursos disponíveis no meio torna-se imprescindivel para a interação dos participantes nas atividades propostas. O desenvolvimento dessa competência foi contemplado no curso de BN, mas não foi previsto no de WE, pois acreditava-se que os alunos matriculados já fossem letrados eletronicamente. Os dados de interação do WE, portanto, mostraram que em várias situações de comunicação foi preciso oferecer ajuda com relação aos conhecimentos eletrônicos para que o aprendiz fosse capaz de solucionar as tarefas propostas pelo curso.

O público-alvo também se diferenciava: no curso de $\mathrm{BN}$ os alunos cursavam graduação e pós-graduação e apresentavam familiaridade com o conhecimento da área de Bioquímica. Entretanto, no curso de WE os alunos se compunham por graduandos de diferentes áreas de conhecimento, cujo interesse comum era o aprendizado da língua inglesa.

\section{Dados considerados na pesquisa}

Para ilustrarmos como se dá o processo de interação e de produção de conhecimentos nos dois cursos analisados e quais são os tipos de andaimes fornecidos pelo professor nesses dois contextos, escolhemos 5 seções de bate-papo do curso de WE, que foi aplicado via ICQ, e 5 seções de chat coletados no curso de BN.

Para a descrição e interpretação dos registros dos chats educacionais dos cursos, optamos por uma metodologia de natureza qualitativa. A escolha dos chats para a análise se deu com base no número de participantes. Assim, optamos pelos que se compunham por 3 alunos, no mínimo. O critério estabelecido para a escolha dos chats se pautou 
pelo fato de que esse número mínimo de participantes era mais produtivo do ponto de vista da interação pedagógica, uma vez que possibilitava perceber o processo de interação professor-aluno e alunoaluno. Esse percurso de análise possibilitou a verificação de como o professor e os alunos interagiam, como eles gerenciavam os turnos das mensagens e, principalmente, como ofereciam os andaimes dentro dos dois cursos.

\section{O Provimento de "Andaimes" (scaffolding) nos Cursos de BN e de WE}

Para análise dos processos de interação sócio-pedagógicos dos cursos de BN e de WE, serão considerados apenas três categorias de andaimes: Ênfase em Traços Críticos (ETC), Demonstração (D) e Controle de Frustração (CF). Os excertos apresentados para a análise mantêm a grafia original, ou seja, a escrita realizada por cada participante é transcrita sem nenhuma alteração.

\section{a) Andaime Ênfase em Traços Críticos - ETC}

De acordo com Bruner et alii. (1976), o andaime Ênfase em Traços Críticos tem como função marcar ou acentuar as características relevantes para a execução da tarefa. Para tanto, o professor pode se valer de diversos meios para atingir esse objetivo. Por meio desse andaime o professor fornece informações sobre a discrepância entre o que o aluno produz e o que ele deveria reconhecer como uma produção correta. Por isso, cabe aos alunos interpretar os aspectos dissonantes existentes na tarefa produzida. Esse procedimento torna-se extremamente útil, pois contribui para que o aluno desenvolva sua capacidade cognitiva na direção da compreensão e da apropriação do conhecimento que está sendo produzido por meio da tarefa. É interessante observar que essa categoria de andaime ajuda o aluno a perceber certas características do processo de aprendizagem que, muitas vezes, são difíceis de ser compreendidas sem a cooperação e colaboração do outro (SILVA, 2003, p. 134).

No contexto virtual do curso de BN e do curso de WE, a categoria de andaime Ênfase em Traços Criticos (ETC) foi a que mais se evidenciou. Isso ocorre porque os participantes da Sala de Discussão 
- professor e alunos - estão a todo momento revendo os conceitos que eles estão discutindo. Essa atitude mostra um forte movimento de natureza colaborativa entre quase todos os participantes da discussão que está sendo promovida por uma dada tarefa. Os dois exemplos abaixo ilustram esse processo de interação entre o professor e os alunos.

\section{Exemplo 1: ETC no curso de Bioquímica da Nutrição}

No exemplo que segue, o professor (Edu), em discussão com dois alunos, apresenta uma performance mediadora na interação sóciopedagógica.

Rodrigo - Mauricio, daí que entra a recomendação da dieta da Zona de selecionar carnes magras. Aliás, eles já calculam que parte da gordura estará veinculada ao grupo das proteínas (Mini-bloco), então, diminuise, ou melhor, modula-se a ingestão de gordura pura conforme a fonte de proteína escolhida...

Mauricio - Edu, acredito que para atletas esta dieta nem pensar mas a varias pessoas que buscam um padrão corporal com o menor \% de gordura possivel e normalmente se exercitam muito. Nestes casos tambem acredito que a dieta $Z$ não se encaixaria.

Edu - Então, vocês vêem que eles não falam em qualquer gordura, falam nas insaturadas, lembram do tal omega 3. Assim como com os carboidratos, se os $40 \%$ jé é pouco, imaginem se coniderar as fibras que não usamos para quase nada, os 40\% viram 30\% fácil, fácil.

lucineia - Rodrigo, insisto com vc sobre quantidade X prporção, pelo que entendi se come muito menos quantidade de cho o que almenta a prp de prt e lip...

Rodrigo - Edu, ainda mais que insentivam o consumo de vegetais, nada contra, mas apresentam maior teor de fibras. Só achei um pecado banir o pão, macarrão...

(Sala 3, 20/09/2001 - Manhã)

É interessante observar que praticamente todas as estruturas lingüísticas das elocuções produzidas pelos participantes dentro da categoria de andaime ETC apresentam uma linguagem formal (científica) e relativamente longa, quando comparada com as conversas informais dentro do mesmo chat. São mensagens produzidas principalmente pelos alunos e revelam um domínio bastante seguro do uso da linguagem técnica necessária para a discussão do conteúdo que está sendo tratado. Ou seja, há um movimento de mudança no grau 
de formalidade da linguagem, que se aproxima mais da escrita de natureza acadêmica, quando ela é usada para apresentar e marcar os conhecimentos práticos/teóricos do aluno, uma vez que esse aluno sabe que sua competência está sendo avaliada.

O excerto abaixo ilustra a função ETC entre alunos, sem a participação do professor. No caso, o andaime ETC está sendo provido pela aluna GRAZI_USP.

mauricio - Quando o figado está produzindo Corpos cetonicos, podocerebro utilizar Corpos cetonicos e glicose como combustivel ao mesmo tempo? Já fiz esta pergunta hoje.

Helena - logged off. - from. using Mozilla/4.51 [en] (Win98; I) on 8/16 at $10: 31 \mathrm{pm}$ GMT)

Zé Henrique - Beleza, mas o "underline não apareceu qdo vc me mandou.. agora vou abusar da sua ajuda...

GRAZI_USP - Eu creio que sim, pois os corpos cetonicos sao produzidos pelo tecido hepatico em situação de depleçaõ de substratos energicos.. pela via gliconeogenica...entao eu acho que o cerebro utiliza as duas fonte sim.

GRAZI_USP - Mauricio..respondi para vc entendeu??? eu acho que é isso.

GRAZI_USP - nao desculpe a glicose que é feita pela via gliconeogenica.... sorry

GRAZI_USP - SORRY....

Zé Henrique - No esquema de estudo aparecem os dois (glicose e corpos cetonicos) ao mesmo tempo como energia para o cérebro... acho que vc está certa.

mauricio - Mas o cerebro não utiliza os corpo cetonicos no sentido de manter o nivel de glicose circulante para preservação dos outros tecidos?

GRAZI_USP - mas o cerebro precisa de um pouco de glicose....ele é um tecido nobre ...nao é como um musculo esqueletico, por exemplo, entao ele utiliza as duas fontes....os cetoacidos e a glicose....

mauricio - O esquema I do modulo 1 exemplifica isto. Mas eu queria confirmar.Valeu!!!

beatriz has timed out.

GRAZI_USP - e ele é um tecido peculiar ...pois nao sao todos os tecidos que obtem os cetoacidos como fonte de energia, então este consumo de cetoacidos indiretamente estara poupando glicose pra outro tecido que nao o utiliza. Como por exemplo as hemacias (se nao me engano) !!! 
Zé Henrique - beleza! Estavamos falando sobre os insulinos dependentes e a formação de corpos cetonicos.... o metabolismo é igual para os não dependentes de insulina?

GRAZI_USP - eu acho que sim, pois ele nao deixa de ser um diabetico, só muda a caracteristica da doença, no caso um nao dependente de insulina tem resistencia a glicose, e isto gerará um desequilibrio metabolico.... eu acho!!!

(Sala 3, 16/08/01 - Vespertino)

Exemplo 2: ETC no curso de WebEnglish

No curso de WE tem-se uma situação distinta. Os alunos são principiantes, ou seja, possuem pouco conhecimento sobre o uso da tecnologia e estão iniciando sua familiarização com a língua inglesa. É interessante observarmos que nesse curso os turnos de mensagem da professora exemplificavam e direcionavam os alunos para as questões essenciais que deveriam ser trabalhadas naquela aula. $\mathrm{O}$ exemplo abaixo ilustra como a professora restringe o direcionamento de questões específicas para o que deve ser trabalhado pelos alunos.

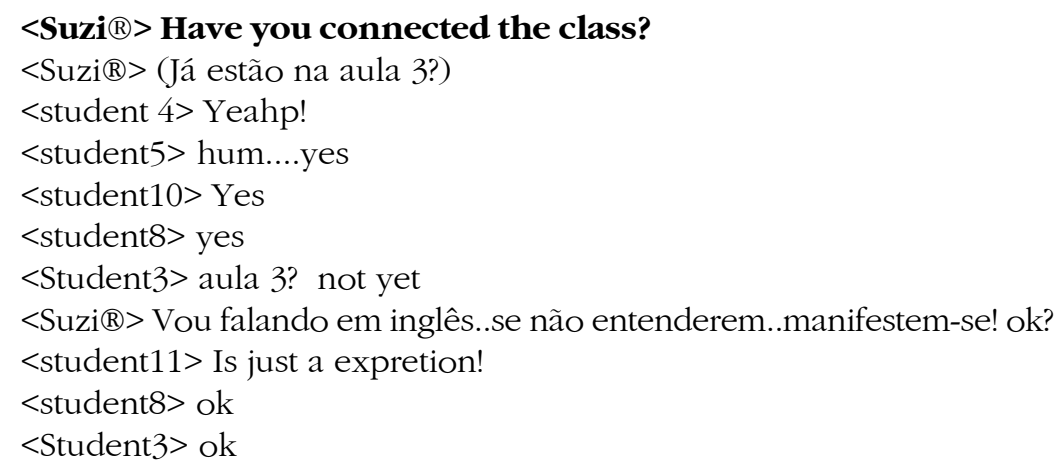

$<$ Suzi ${ }^{\circledR}>$ What's our class 3 about?

$<$ Student3> wait a minute

$<$ student5> yes.teacher

$<$ student $4>$ We have to talk about ourselves!

$<$ Suzi ${ }^{\circledR}>$ oh... What specifically about ourselves?

$<$ student8> discribe likes and dislikes

$<$ Student $3>$ the things that we like and dislike

$<$ student $4>$ Our likes and disikes...

(Fragmento 8 - sessão de bate-papo E1 D - 06/08/2002)

Alertar, então, o aluno para o que é realmente essencial parece se sustentar em dois motivos: o primeiro é a necessidade de o professor 
receber um feedback do aluno para monitorar e verificar se ele está entendendo o que foi proposto; o segundo está relacionado à necessidade do professor de orientar o aluno na resolução da tarefa proposta, negociando com ele os significados não compreendidos.

\section{b) Andaime de Demonstração-D}

Durante as experiências desenvolvidas por Bruner et alii (1976), os pesquisadores observaram que havia situações em que o professor (tutor) tinha que demonstrar para o aluno como é que ele deveria proceder para realizar a atividade proposta. Por essa razão, esse tipo de andaime foi denominado pelos autores de Demonstração. Nesse contexto, a função do professor é de servir como um modelo para que o aluno o 'imite' passo a passo, e consiga, assim, realizar a tarefa.

A demonstração, no contexto presencial, é uma 'exibição' que o professor faz de uma determinada tarefa, que implica mostrar 'como' se faz, para que os alunos repitam, então, a ação demonstrada pelo professor. No contexto do chat, a Demonstração é eminentemente descritiva, pois a linguagem gráfica se torna o único meio mediador de demonstração entre os participantes. Nos exemplos que se seguem, apresentamos a função. Demonstração nos dois contextos de análise, ou seja, nos cursos de BN e de WE.

\section{Exemplo 1: Demonstração no curso de Bioquímica da Nutrição}

Embora o exemplo de andaime de demonstração, no excerto abaixo, não seja específico do conteúdo do curso, podemos verificar a aluna (Mirian) demonstrando para a colega (pri) e para a professora (Mary) como elas devem proceder para configurarem o emoticon carinha feliz - : ). Os emoticons são símbolos que se caracterizam como mensagens, pois eles carregam significados, como raiva, alegria, tristeza, ódio, entre outros. Dessa forma, eles podem também ser usados como complemento da estrutura lingüística da mensagem. Por exemplo, ao invés de o aluno escrever que entendeu a explicação dada pelo professor, ele pode simplesmente inserir o emoticon 'carinha feliz' para expressar que compreendeu.

Mirian - everybody!!!!!!!

mirian - ah !!!^-^

pri-Oi Marcio, faço Química na Unicamp 


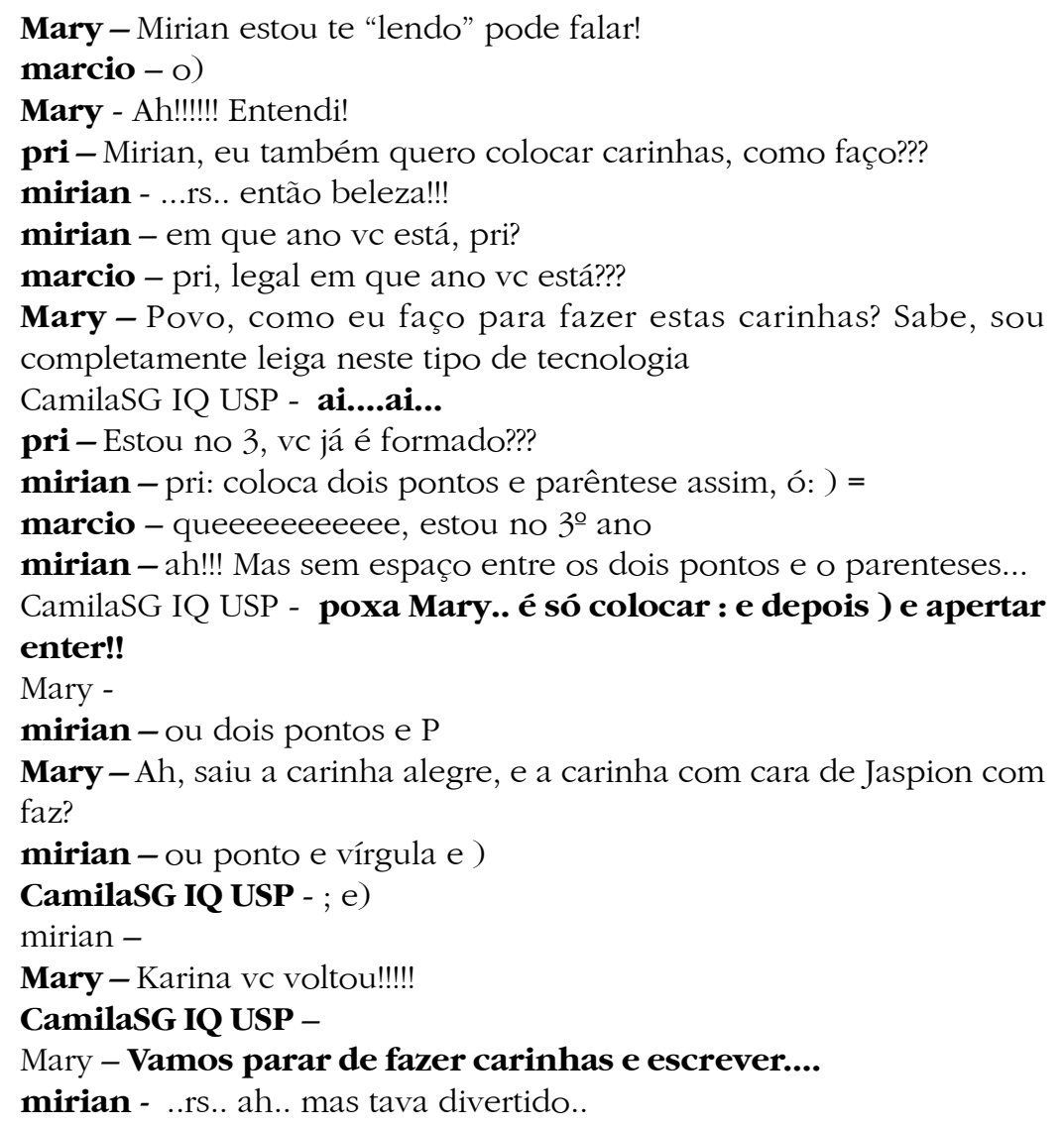

(Sala 5, 03/08/01 - Vespertino)

Exemplo 2: Demonstração no curso de WE

No curso de WE o andaime Demonstração é manifestado quando o professor modela estruturas lingüísticas ou exemplifica situações reais de comunicação que o aluno poderá desenvolver ao se comunicar na web. No curso, a Demonstração-seja com exemplos de algum aspecto lingüístico ou com a descrição dos procedimentos que levam à realização de uma determinada tarefa em discussão na aula - é dificultada pelo fato de a professora não poder comunicar-se usando recursos extralingüísticos. Para contornar essa situação, ela ilustra situações de uso da linguagem que estão sendo estudadas naquele momento e descreve, em detalhes, os procedimentos que o aluno precisa fazer para realizar sua tarefa. 
Essa questão pode ser observada nos exemplos \#4 e \#5. Nessas situações, pode-se observar a atuação da professora em uma aula na qual ela busca levar os alunos à discussão sobre preferências pessoais. No exemplo \#4, a professora facilita a discussão fazendo uma afirmação pessoal sobre sua preferência e elaborando uma questão que convida os alunos a fazerem o mesmo. O exemplo indica também que o andaime Demonstração pode ser oferecido durante a tarefa, pelos alunos, como mostra a intervenção do aluno 3 (sublinhada) em resposta à solicitação do aluno 11 .

\#4

$<$ student $4>$ Our likes and disikes...

<student11> I want to know how to put collor in my words. (dúvidas do aluno)

$<$ Suzi ${ }^{\circledR}>$ Oh.. Great.!!! BTW, I LOVE CHOCOLATE, how about u?

$<$ student $4>$ Me tooooooooo!!!!!

$<$ student $4>$ But I prefer white chocolate...

$<$ student10> Everybody love chocolate...

$<$ Student3 $>$ dany.. in the topo has a box with colors...

$<$ student8> I love chocolate much more

(Fragmento 4 - sessão de bate-papo E1 D - 06/08/02)

Os exemplos \#5 e \#6 ilustram outras situações similares. No primeiro, a professora orienta o aluno sobre como mudar a visualização do chat. No segundo, a mesma explica como o aluno pode alterar o tamanho da letra usada no chat.

\#5

$<$ student $4>$ Suzi, my chat view is different today. Why is that?

$<$ Suzi ${ }^{\circledR}>$ Where is st11?

$<$ Suzi ${ }^{\circledR}>$ Just click on the Menu LAYOUT and select IRC mode

$<$ Suzi ${ }^{\circledR}>$ sorry IRC style

$<$ student 4> I got it Suzi!

(Fragmento 1 - sessão de bate-papo E1 D - 08/08/02)

\#6

$<$ student11 $>$ Como eu faço pra minha letra ficar mais grossa?

$<$ Suzi ${ }^{\circledR}>$ vamos verificar aqui em conjunto.. a pagina esta com um

probleminha técnico

$<$ student 4> But I've already did it...

$<$ student11 $>$ Me too

$<$ Suzi ${ }^{\circledR}>$ clica em BOLD - lá em cima no menu.. 


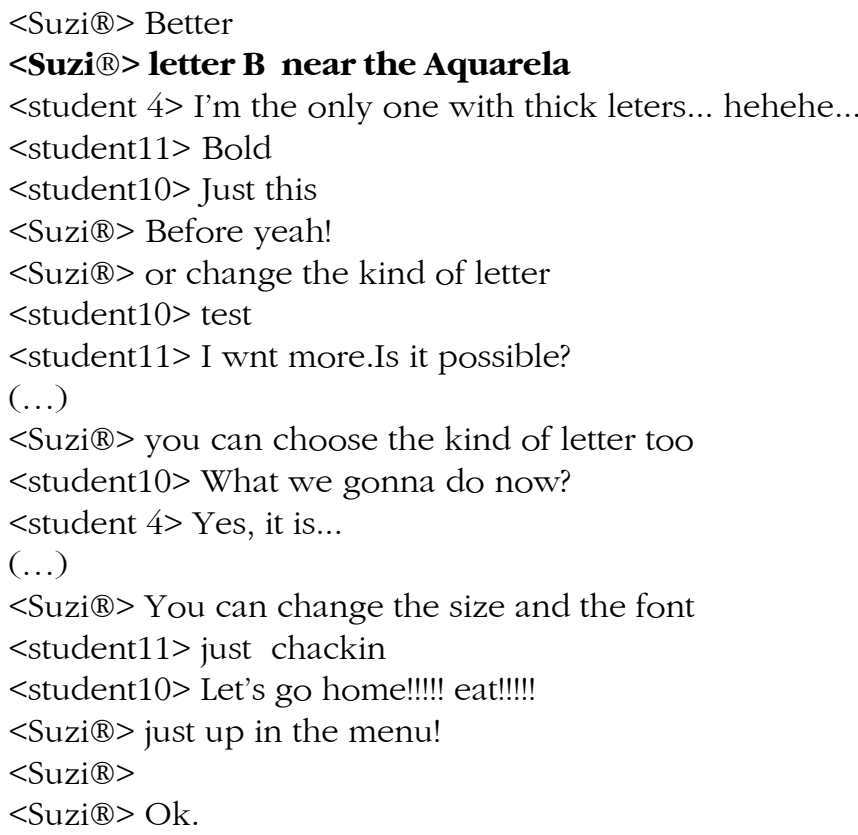

(Fragmento 6 - sessão de bate-papo E1 D - 08/08/02)

Ao analisar o fragmento acima, nota-se que, embora a maioria das intervenções da professora nas aulas iniciais objetive solucionar problemas de ordem técnica, os problemas lingüísticos também são foco da intervenção pedagógica. No fragmento \#7, a professora faz uso de uma nova estrutura lingüística para exemplificar e esclarecer a dúvida dos aprendizes com relação à tarefa que eles têm para realizar. Mais especificamente, os alunos não tinham entendido como deveriam proceder para realizar a atividade: na tarefa anterior, eles haviam feito uma entrevista com o Mr. Hide, buscando identificar as preferências desse com relação a tipos de comida, esporte, filmes, etc.; na tarefa em foco, pedia-se aos alunos que contrastassem as preferências do Mr. Hide com as suas.

\#7

$<$ student8> suzy we don't understand what we have to do (dúvida do aluno)

$<$ Suzi ${ }^{\circledR}>$ Yeah, for example,: My favorite Singer is Celine, but Mr Hide likes foo fighters

(Fragmento 7 - sessão de bate papo E1 D - 06/08/02) 
Embora essas situações de exemplificação e de referências a situações reais de uso da língua alvo também ocorram no ensino presencial, na aula virtual, a única maneira de ilustrar é modelando um exemplo no momento da interação no chat. Talvez uma outra forma de "ilustrar" virtualmente fosse possível, ao recorrer, por exemplo, ao uso de recursos multimídia que possibilitassem a ilustração ao aprendiz, por exemplo, através de imagens, animações. No entanto, nas situações de chat analisadas, a professora não faz uso de outro recurso além da linguagem escrita.

\section{c) Andaime de Controle de Frustração (CF)}

O processo de aprendizagem pode ser uma experiência pouco confortável para o aluno, pois, dependendo do grau de dificuldade requerido pela tarefa, ele pode se sentir frustrado por não poder executá-la com sucesso. Esse 'estresse' pode estar relacionado com o fato de o aluno não ter entendido como é que a tarefa deve ser realizada, como também pode estar relacionado com o fato de o aluno não ter pré-requisitos suficientes para compreender e expandir o conhecimento que o professor espera que ele adquira.

Para Bruner et alii (1976), a solução de um problema pode ser menos 'sinistra' e menos estressante quando o aluno pode contar com a ajuda de uma pessoa mais competente, em particular, com a ajuda do professor. Quando isso ocorre, o grau de frustração experimentado por ele tende a diminuir ou ser completamente dirimido. Os autores observam que é importante que o professor tenha cuidado para lidar com o sentimento de frustração do aluno, pois dependendo da forma como isso se realiza, esse sentimento pode gerar situações que comprometem a autoconfiança e a independência. Em alguns casos, o grau de excitação, de incerteza e de frustração experimentado pelo aluno pode se manter mesmo após a conclusão com êxito da tarefa. Essa categoria de andaime também se evidencia no processo de interação dos dois cursos.

Exemplo 1: Controle de Frustração no curso de BN

No excerto abaixo, a professora (KINHA) procura controlar a frustração apresentada pela aluna mauriceia.

Mauriceia - nem me fale deste modulo $1 \ldots$

KINHA - Sinto muito Mauricéia, mas só iremos falar nele!!!! 
KINHA - Pode desabafar comigo, sou toda leitura...

KINHA - ...ou melhor leitora

mauriceia - Eu senti muitas dificuldades neste inicio, acho que levei foi um susto...

KINHA - Muitos alunos tiveram dificuldade em conceitos básicos de bioquímica, vc não foi a única e por está razão resolvemos abrir essa sala de discussão. Mas e aí? O susto passou ou ainda resta alguns monstrinhos de bioquímica??

mauriceia - Esta passando.

mauriceia - Quebrei a cabeca com o ciclo de krebs, Acho que fiquei pensando nele como quimica, e ai a coisa desandou. eu ficava tentando saber tudo que esta envolvido em cada etapa...

KINHA - E qual foi sua conclusão?

mauriceia - Foi a de que preciso estudar mais... :-)))))

KINHA - Isso é bom, estamos tendo resultados!!!

(Sala 3, 16/08/01 - Noturno)

Exemplo 2: Controle de Frustração no curso de WE

Nas sessões de chat analisadas, o exemplo \#7 ilustra que as alunas 5 e 6 estão (totalmente) perdidas e clamam por auxílio da professora. Ao atender o pedido da aluna 5 , a professora tenta minimizar seu estresse, falando-lhe de maneira descontraída.

\#7

$<$ Student3 $>$ who is the st11...I love popcorn...You say that because you never eat..I guess

<student5> estou perdida.......acho (aluno requer auxilio da professora)

$<$ student11 $>$ who taked the same collor that I?YOU better change

$<$ student10 $>$ Candi are you the st 3

$<$ student8> she is

$<$ Suzi ${ }^{\circledR}>$ Oh, fala ai Angelise!

<student6> Desculpa!Estou totalmente perdida! (aluno requer auxilio da professora)

$<$ student5> ;-/

$<$ Suzi ${ }^{\circledR}>$ hmmm vamos lá..eu pedi sobre o tópico da aula ne?

(...)

$<$ student10 $>$ who's is 4

$<$ student10 $>$ Hello who are you?

$<$ Student3> 4 is Lucy

$<$ student 4> I'm Lulu!

$<$ Suzi ${ }^{\circledR}>$ Pessoal..digam os nomes primeiros... :) Vamos ajudar o numero 6 e 4 (professora busca minimizar o stress da aluna) 


$$
\begin{aligned}
& \text { <student5> Hi Deby! } \\
& \text { <student5> ok } \\
& \text { <student5> I'm Angelise }
\end{aligned}
$$

$<$ Suzi ${ }^{\circledR}>$ Ta, pessoal..todos já sabem q o tópico da aula, é sobre likes e dislikes..

$<$ student10> Hi Luci

$<$ student8 $>$ the namber 4 and 6 write now

$<$ Suzi ${ }^{\circledR}>$ todos entenderam isso? (professora espera feedback dos alunos)

(...)

\section{$<$ Suzi ${ }^{\circledR}>$ Let's go to the Hyperlink "Likes and dislikes"}

$<$ student5> hum...acho que to me achando......teacher

(Fragmento 7 - sessão de bate-papo E1 D - 06/08/02)

Tanto na aula a distância quanto na presencial, a professora recorre ao uso da LM como uma forma de diminuir o estresse dos alunos. Ou seja, o uso da LM na aula a distância também leva a aluna a se sentir mais à vontade, já que não há pressão psicológica de ter que compreender em LE. Ao simplificar a tarefa em LM, a professora possibilita que a aluna compreenda e seja capaz de realizar o exercício.

O exemplo \#8 ilustra outra situação de estresse: o aluno reclama com a professora sobre o tempo das atividades. Ao fazer uso de letras maiúsculas, o aluno manifesta que não está contente. Ao detectar esse fato, a professora brinca com o aluno e tenta justificar porque está acelerando a condução das atividades. Com essa "brincadeira", a mesma tenta manter o aluno calmo, tranqüilizando-o para que faça suas atividades dentro do tempo que ele achar necessário.

\#8

$<$ student11> I'm telling YOU NEVER GIVE US ENOUGHT TIME TO READY AND DO OUR TESKS

$<$ Suzi ${ }^{\circ}>$ ohhhh..sorry..

$<$ Suzi ${ }^{\circledR}>$ Am I running?

$<$ Suzi®> :)

$<$ Suzi ${ }^{\circledR}>$ dont worry..be calm...

$<$ student11> I'm

$<$ Suzi ${ }^{\circledR}>$ I just trying to help the faster students..

$<$ Suzi ${ }^{\circledR}>$ but dont get panic!

$<$ Suzi ${ }^{\circledR}>$ :)

$<$ Suzi ${ }^{\circledR}>$

$<$ Suzi ${ }^{\circledR}>$ Beep! Beep! 
<student $4>$ Ok, Suzi... I did it...

$<$ student11> Class 5 here we go

(Fragmento 35 - sessão de bate-papo E1 D -13/08/02)

Em contextos virtuais parece ser fundamental que o professor mantenha os alunos motivados para interagirem e serem capazes de trabalhar autonomamente. No entanto, essa não é uma tarefa fácil de ser realizada no ensino/aprendizagem de LE, principalmente se os alunos forem iniciantes e não souberem a língua-alvo. Temos que levar em consideração também que existe uma série de outros fatores que podem desmotivar esses alunos a atuar com maior autonomia na web, como, por exemplo, as dificuldades de interação com o meio eletrônico, por não serem letrados eletronicamente. Talvez, desenvolver a interação entre os participantes do curso seja uma forma de possibilitar que os alunos, ao trabalharem colaborativamente com os colegas, não se sintam tão desmotivados para solucionar as atividades propostas em aula. No entanto, o desenvolvimento da interação e da colaboração parecem depender do tipo de atividade proposta ao aluno e da capacidade do professor de mediar e prover andaimes que facilitem a consecução da tarefa (REIS, 2004, p. 109).

\section{Conclusões}

A análise dos dois cursos permitiu verificar que há ainda necessidade de se aprofundarem os estudos teóricos sobre essa nova forma de interação que leva à construção do conhecimento via web, pois a cultura de ensinar e aprender na rede tem particularidades que se distinguem da modalidade presencial. Além disso, é importante perceber que as interações pedagógicas dentro dessa nova cultura também são afetadas pelas especificidades relativas ao conteúdo programático dos cursos, como ocorre no ensino presencial.

Os resultados mostrados pela análise das três categorias de andaimes eleitos para o presente estudo indicam que há especificidades que se marcam em função da mudança de contexto nos quais eles foram providos. Ou seja, o provimento de andaimes no estudo de Bruner et alii (1976) aconteceu num contexto presencial, no qual a interação sócio-pedagógica se dava entre o professor e crianças com idade entre 3 e 5 anos. A mediação era feita, então, através da linguagem oral e, 
portanto, podia recorrer ao vasto repertório de ações extralingüísticas, tais como gestos e expressões faciais.

Através deste estudo foi possível perceber que o provimento de andaimes no meio virtual exige um refinamento das categorias propostas pelos pesquisadores, bem como indica a possibilidade de ampliação do modelo apresentado pelos autores, uma vez que as particularidades do meio virtual parecem indicar outras categorias possíveis e mais representativas dessa nova modalidade de ensino.

Um aspecto que nos parece relevante no uso das novas tecnologias de ensino é o de planejar os cursos de forma a discutir, prever e informar os aprendizes sobre os problemas mais recorrentes em um contexto digital. Da mesma forma, é necessário delimitar o papel do aluno e do professor nesses contextos, pois a clareza do compromisso que cada um deve assumir pode proporcionar uma maior autonomia por parte dos aprendizes e reforçar a necessidade da sua colaboração, cooperação e compreensão.

\section{Referências}

ALMEIDA FILHO, J.C.P.de. Dimensões comunicativas no ensino de linguas. Campinas: Pontes, 1993. p. 47-53.

ANTÓN, M. The discourse of aimed-centered classroom: sociocultural perspectives on teacher-leamed interaction $\mathrm{m}$ the second-language classroom. The Modem Language Journal, 83, iii, 1999.

BRUNER, J. S. Toward a theory of instruction. Cambridge. Mass: Belknap, 1966.

BRUNER, J. S.; WOOD, D.; ROSS, G. The role of tutoring in problem solving. Journal of child psychology \& psychiatry, 17, 1976, p. 89-100.

BUZATO, M. O letramento eletrônico e a inserção do computador na aula de língua estrangeira. 2001. Dissertação (Mestrado) - IEL/UNICAMP, Campinas - SP.

MOTTA-ROTH, D.; REIS, S.C.; BORTOLUZZI, V. I. Interação e motivação em um curso de inglês mediado por computador. Idéias. Santa Maria, RS: UFSM, n. 12, p. 55-59, jul./dez. 2000. 
MOTTA-ROTH, D. De receptador de informação a construtor de conhecimento: $\mathrm{O}$ uso de chat no ensino de inglês para formandos de Letras. In: PAIVA, V. L. M. de O. e. (Org.). Interação e aprendizagem em ambiente virtual. Belo Horizonte: Faculdade de Letras, UFMG, 2001. p. 230-48.

PAIVA, V. L. M. de O. e. Aprendendo inglês no ciberespaço. In: MENEZES, V. (Org.). Interação e aprendizagem em ambiente virtual. Belo Horizonte: Faculdade de Letras, UFMG, 2001. p. 270-305.

REIS, S.C. dos. A intervenção pedagógica do professor em contextos diferenciados: a oferta de andaimes na aula presencial e a distância. 2004. Dissertação (Mestrado) - IEL, UNICAMP, Campinas, SP.

SILVA, V. Interação social e estratégias lingüisticas no processo de provimento de andaimes - scaffolding - em uma disciplina de Bioquímica da Nutrição oferecida a distância via computador. 2003. Dissertação (Mestrado) DLA/IEL/UNICAMP, Campinas, SP.

VYGOTSKY, L. S. Pensamento e linguagem. São Paulo: Martins Fontes, 1989.

WIDDOWSON, H.G. O ensino de linguas para a comunicação. Trad. José Carlos Paes de Almeida Filho. Campinas: Pontes, 1991.

YOKAICHIYA D. K. O ensino a distância aplicado a uma disciplina de Bioquímica - Bioquímica da Nutrição. 2001. Dissertação (Mestrado) Instituto de Biologia UNICAMP, Campinas, SP. 